\title{
Field Test of Electrochemical Degradation and Oil-Removal Technology Used the Treatment of Wastewater Containing Polymer in Offshore Oilfield
}

\author{
Mengying Yang1, Qing Li ${ }^{1}$, Xianqing Yin ${ }^{*}$, Lei Zhai ${ }^{2,3}$, Bo Jing ${ }^{2,3}$ \\ ${ }^{1}$ College of Chemical and Environmental Engineering, Yangtze University, Jingzhou, China \\ ${ }^{2}$ State Key Laboratory of Offshore Oil Exploitation, Beijing, China \\ ${ }^{3} \mathrm{CNOOC}$ Research Institute, Beijing, China \\ Email: "jzyinxq@126.com
}

Received 27 July 2015; accepted 5 December 2015; published 8 December 2015

Copyright (C) 2015 by authors and Scientific Research Publishing Inc.

This work is licensed under the Creative Commons Attribution International License (CC BY).

http://creativecommons.org/licenses/by/4.0/

(c) (i) Open Access

\begin{abstract}
Aimed at the current treatment status of the polymer-flooding wastewater in Bohai oilfield, electrochemical technology used for polymer-degradation and oil-removal was researched. It formed the process flow of cyclone mixed dosing $\rightarrow$ electrochemical removal oil $\rightarrow$ inclined tube removal oil $\rightarrow$ walnut shell filter, and a set of skid mounted wastewater containing polymer treatment plant was designed and manufactured, which was used for the field test of electrochemical treatment of wastewater containing polymer in offshore oilfield. The result shows that the oil removal rate of the electrochemical treatment process is over $\mathbf{9 8 \%}$, and the synergistic effect is significant especially used in conjunction with water clarifier of BHQ-04. When the amount of water clarifier is $50-150 \mathrm{mg} / \mathrm{L}$, the oil content, the median particle diameter and the suspended solids content of the filtered water is $8-18 \mathrm{mg} / \mathrm{L}, 1.9-2.26 \mu \mathrm{m}$ and $1.39-2.04 \mathrm{mg} / \mathrm{L}$ respectively, which reach the scene water quality standards for water injection.
\end{abstract}

\section{Keywords}

Electrochemical Removal Oil, Wastewater Containing Polymer, Synergistic Effect, Field Test

\section{Introduction}

Polymer flooding is an effective technique for the offshore oil exploitation; however the polymer-return in pro-

${ }^{*}$ Corresponding author.

How to cite this paper: Yang, M.Y., Li, Q., Yin, X.Q., Zhai, L. and Jing, B. (2015) Field Test of Electrochemical Degradation and Oil-Removal Technology Used the Treatment of Wastewater Containing Polymer in Offshore Oilfield. Journal of Water Resource and Protection, 7, 1409-1415. http://dx.doi.org/10.4236/jwarp.2015.717114 
duced liquid is a serious phenomenon along with the scale expansion of polymer injection and the continuous improvement of liquid yield [1]. Wastewater containing polymer is a kind of complex system formed of oil/water emulsion mixed with inorganic solid, and it has the characteristics of high viscosity, serious emulsification, complex composition, smaller oil droplet size and large amount of sludge compared with conventional produced water [2]-[4], which increases the processing difficulty. How to achieve the standard treatment of wastewater containing polymer efficiently and effectively has become a problem to be solved urgently in the offshore oilfield because of the short processing time and the limited space on the offshore platform [5].

According to the characteristics of wastewater containing polymer, this study applies the electrochemical technology to realize the integration of degradation and oil-removal of wastewater containing polymer. And a set of skid mounted wastewater containing polymer treatment plant was designed and manufactured [6], which was used for the field test of electrochemical treatment of wastewater containing polymer in offshore oilfield. The expected result has been achieved and it has a great significance to guide the transformation of the site process equipments.

\section{Mechanisms of Electrochemical Technology}

Electrochemical method is a kind of environmental friendly wastewater treatment method which has less secondary pollution, and it is widely used in water treatment field with the advantages that many traditional water treatment processes lacks. It has characteristics of wide treatment range, strong treatment capability, no or few secondary pollution, multi functional and flexible, easy to control, small area, simple post processing, product stability and so on. In this experiment, inert electrode and DC power supply with low voltage low current (voltage is $\leq 30 \mathrm{~V}$, current is $\leq 120 \mathrm{~A}$ ) is used to conduct the test [7], and there are primary two kinds of reactions on the electrode in this condition.

1) Electrolytic flotation is due to the dissociation of water and electrolytic oxidation of other substances and produce $\mathrm{H}_{2}$ and $\mathrm{O}_{2}$ micro bubble with small bubble particle size (20 to $50 \mu \mathrm{m}$ ) and low density on the surface of the electrode. Because of their strong adsorption capacity and floating load capacity, these micro bubbles can rapidly absorb emulsified oil droplet and suspended solids of wastewater to form clumps and float to the surface of water, which play a role in fast flotation separation, and enhance the effectiveness of oil removal.

Anodic reaction:

$$
\begin{gathered}
4 \mathrm{OH}^{-}-4 \mathrm{e} \rightarrow 2[\mathrm{O}]+2 \mathrm{H}_{2} \mathrm{O} \rightarrow \mathrm{O}_{2} \uparrow+2 \mathrm{H}_{2} \mathrm{O} \\
\mathrm{Cl}^{-}+2 \mathrm{OH}^{-}-2 \mathrm{e} \rightarrow \mathrm{ClO}^{-}+\mathrm{H}_{2} \mathrm{O}
\end{gathered}
$$

Cathode reaction:

$$
2 \mathrm{H}^{+}+2 \mathrm{e} \rightarrow 2[\mathrm{H}] \rightarrow \mathrm{H}_{2} \uparrow
$$

2) Electrolytic redox reactions refer to oxidation reactions on the anodic and reduction reactions on the cathode. Free radical ( $\left.\cdot \mathrm{OH}, \mathrm{HO}_{2} \cdot{ }^{\cdot} \cdot \mathrm{O}_{2}\right)$ and strong oxidizing substances $\left(\mathrm{O}_{3}, \mathrm{H}_{2} \mathrm{O}_{2}, \mathrm{ClO}^{-}\right)$produced during electrolytic process oxidize and degrade polymer and emulsified oil, meanwhile this process is irreversible. For example, active free radical $(\cdot \mathrm{OH})$ produced during the reaction acts on residual polymer PAM of the wastewater with rapid oxidation reaction and free radical chain reaction resulting in the partial or complete degradation of polymer. In addition, some organic free radicals (RCOO·, RCO·) probably produce during PAM molecular bond cleavage, and conversely work on PAM molecules to make them degraded. Perhaps PAM molecules are directly oxidized to PAM small molecule, acrylamide monomer, acrylic acid and other small groups. At the same time, some small molecules or groups can be further degraded into $\mathrm{CO}_{2}, \mathrm{H}_{2} \mathrm{O}, \mathrm{NO}_{3}^{-}$and $\mathrm{N}_{2}$ to realize the complete degradation of the polymer [8] [9]. The degradation reaction of PAM is as follows:
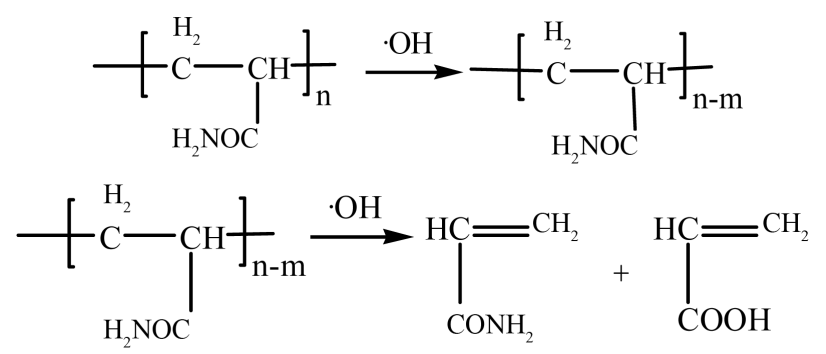


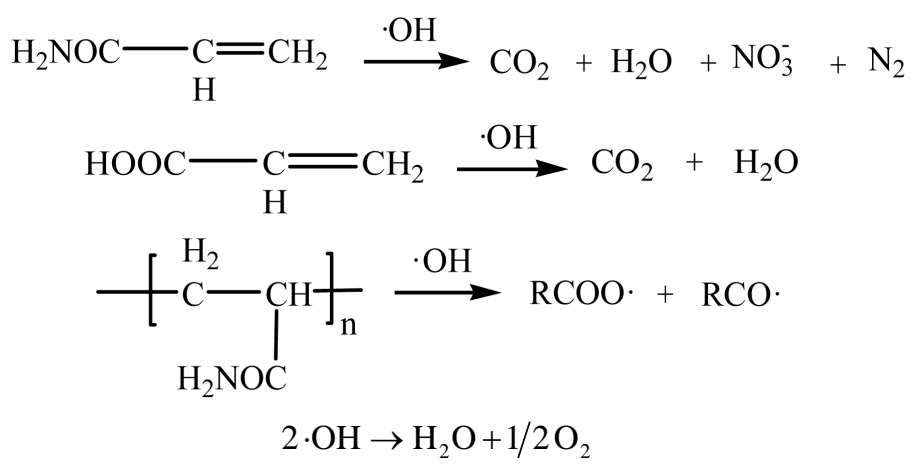

\section{Material and Methods}

\subsection{Technology Introduction}

Aiming at the problems such as the water quality is not up to the standard for serious emulsification and high stability of the site wastewater containing polymer and low efficiency of the equipment, as well as water clarifiers increase the aggregation of oil sludge causing sludge treatment flowsheet blockage, the optimization of the process of wastewater treatment is studied. The best combined process and operating parameters are obtained by applying electrochemical degradation technology, simulating the site unit equipment and developing process optimization [10]-[14]. And a set of $10 \mathrm{~m}^{3} / \mathrm{d}$ skid mounted wastewater containing polymer treatment plant was designed and manufactured, which was used for the field test of electrochemical treatment of wastewater containing polymer in CEPK platform of SZ36-1 oilfield.

This plant consists of the unit equipments of cyclone dosing mixing tank [15], electrochemical oil-remover, inclined tube separator, walnut shell filter and so on, forming the whole treatment process of wastewater containing polymer including cyclone mixed dosing $\rightarrow$ electrochemical removal oil $\rightarrow$ inclined tube removal oil $\rightarrow$ walnut shell filter as shown in Figure 1. The treatment plant works independently with the wastewater containing polymer introduced from a sewage separator outlet pipe confluence of produced liquid process flow during the field test, and it would not affect the existing wastewater treatment process.

\subsection{Test Scheme}

The field test applies continuous operation process, and the flow sets $450 \mathrm{~L} / \mathrm{h}$. The oil content of wastewater containing polymer with temperature of $60^{\circ} \mathrm{C}$ is about $4000-5000 \mathrm{mg} / \mathrm{L}$. The added water clarifier is BHQ-04 been using in the platform. And the residence time of wastewater in electrochemical oil-remover and inclined tube separator is both $20 \mathrm{~min}$. Specific process scheme is as shown Table 1.

The water samples collected from different sample connections including imported water sample, electrochemical oil-remover output, inclined tube separator output and walnut shell filter output are used to determine the oil content when the process is stable for $30 \mathrm{~min}$ and $60 \mathrm{~min}$ respectively. And the filtered water samples are for the index analysis of particle diameter, suspended solid content and turbidity. The analysis methods are based on this standard of 5329 - 2012 SY/T "Water quality standard and practice for analysis of oilfield injecting waters in clastic reservoirs".

\section{Results and Discussion}

\subsection{Water Quality of Total Process Test}

Process One: The oil contents of different sample connections with four different dosages of water clarifier

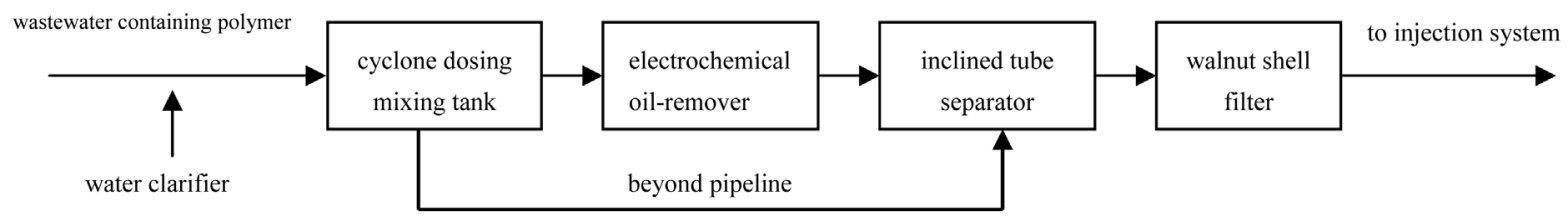

Figure 1. Process flow chart of wastewater containing polymer treatment plant. 
when the process is stable for 30 min and 60 min respectively are shown in Table 2.

Table 2 shows the remarkable oil removal efficiency when the process with electrochemical technology is stable and the oil contents of the filtered water samples which are clear and transparent are all under $20 \mathrm{mg} / \mathrm{L}$. The slight decrease of the oil content with the increase of electrolysis time reveals the treatment efficiency is jarless when the process is stable. Without the water clarifier BHQ-04, the oil contents of the output of electrochemical oil-remover and inclined tube separator are $73-85 \mathrm{mg} / \mathrm{L}$ and $64-70 \mathrm{mg} / \mathrm{L}$ respectively, which are significantly higher than those with water clarifier. Thus it will aggravate the pollution of filter media and operating load. The oil contents of different sample connections are stable along with the increased dosages of BHQ04 indicates the good synergistic effect between electrochemical technology and water clarifier, and the oil removal efficiency of electrochemical technology with moderate BHQ-04 (50 - $100 \mathrm{mg} / \mathrm{L})$ more higher.

Process Two: The test results of the process without electrochemical technology are shown in Table 3.

Table 3 shows the oil content and turbidity of water samples of inclined tube separator output present downtrend with the water clarifier BHQ-04 of 150 - $200 \mathrm{mg} / \mathrm{L}$ during the process operating without electrochemical technology. The increased dosages of BHQ-04 can probably improve the water quality; however the reagent cost is bound to increase and the rising amount of viscoelastic sludge because of the adding reagent will cause blockage to the following processes.

Table 1. Specific process scheme of the test.

\begin{tabular}{ll}
\multicolumn{1}{c}{ Process } & \multicolumn{1}{c}{ Specific Process Scheme } \\
\hline \multirow{2}{*}{ Process One } & $\begin{array}{l}\text { Wastewater containing polymer }+ \text { Water clarifier BHQ-04 } \rightarrow \text { Cyclone dosing mixing tank } \rightarrow \text { Electrochemical } \\
\text { oil-remover } \rightarrow \text { Inclined tube separator } \rightarrow \text { Walnut shell filter } \rightarrow \text { Filtered water }\end{array}$ \\
& Dosage of water clarifier: $0 \mathrm{mg} / \mathrm{L}, 50 \mathrm{mg} / \mathrm{L}, 100 \mathrm{mg} / \mathrm{L}, 150 \mathrm{mg} / \mathrm{L}$ \\
& Wastewater containing polymer + Water clarifier BHQ-04 $\rightarrow$ Cyclone dosing mixing tank $\rightarrow$ Inclined tube \\
Process Two & separator $\rightarrow$ Walnut shell filter $\rightarrow$ Filtered water \\
& Dosage of water clarifier: $150 \mathrm{mg} / \mathrm{L}, 200 \mathrm{mg} / \mathrm{L}$ \\
\hline
\end{tabular}

Table 2. Oil content of water quality at all levels of the whole process in process one.

\begin{tabular}{|c|c|c|c|c|c|c|}
\hline \multirow[b]{2}{*}{$\begin{array}{c}\text { Dosages of } \\
\text { BHQ—04/mg/L }\end{array}$} & \multirow{2}{*}{$\begin{array}{c}\text { Stable } \\
\text { Process } \\
\text { Time/min }\end{array}$} & \multicolumn{4}{|c|}{ Oil Contents from Different Sample Connections /mg/L } & \multirow{2}{*}{$\begin{array}{l}\text { Appearance of } \\
\text { Filtered } \\
\text { Water }\end{array}$} \\
\hline & & $\begin{array}{c}\text { Imported } \\
\text { Water Sample }\end{array}$ & $\begin{array}{l}\text { Electrochemical } \\
\text { Oil-Remover } \\
\text { Output }\end{array}$ & $\begin{array}{c}\text { Inclined Tube } \\
\text { Separator } \\
\text { Output }\end{array}$ & $\begin{array}{l}\text { Walnut Shell } \\
\text { Filter Output }\end{array}$ & \\
\hline \multirow{2}{*}{0} & 30 & 4180 & 70 & 85 & 11 & \multirow{8}{*}{$\begin{array}{l}\text { Clear and } \\
\text { transparent }\end{array}$} \\
\hline & 60 & 4180 & 64 & 73 & 9 & \\
\hline \multirow{2}{*}{50} & 30 & 3960 & 65 & 56 & 10 & \\
\hline & 60 & 3960 & 54 & 44 & 11 & \\
\hline \multirow{2}{*}{100} & 30 & 4140 & 62 & 39 & 18 & \\
\hline & 60 & 4140 & 45 & 41 & 13 & \\
\hline \multirow{2}{*}{150} & 30 & 4140 & 42 & 48 & 12 & \\
\hline & 60 & 4140 & 41 & 37 & 8 & \\
\hline
\end{tabular}

Table 3. Water quality of all levels of the whole process in process two.

\begin{tabular}{|c|c|c|c|c|c|c|}
\hline \multirow[b]{2}{*}{$\begin{array}{c}\text { Dosages of } \\
\text { BHQ- }-04 / \mathrm{mg} / \mathrm{L}\end{array}$} & \multirow[b]{2}{*}{$\begin{array}{c}\text { Stable Process } \\
\text { Time/min }\end{array}$} & \multicolumn{3}{|c|}{ Oil Contents from Different Sample Connections /mg/L } & \multirow[b]{2}{*}{$\begin{array}{c}\text { Turbidity of } \\
\text { Inclined Tube } \\
\text { Outlet/NTU }\end{array}$} & \multirow[b]{2}{*}{$\begin{array}{l}\text { Appearance of } \\
\text { Filtered Water }\end{array}$} \\
\hline & & $\begin{array}{c}\text { Imported Water } \\
\text { Sample/mg/L }\end{array}$ & $\begin{array}{c}\text { Inclined Tube } \\
\text { Separator } \\
\text { Output/mg/L }\end{array}$ & $\begin{array}{c}\text { Walnut Shell Filter } \\
\text { Output /mg/L }\end{array}$ & & \\
\hline \multirow{2}{*}{150} & 30 & \multirow{2}{*}{4430} & 210 & 118 & 141 & \multirow{4}{*}{$\begin{array}{l}\text { Pale yellow and } \\
\text { opaque }\end{array}$} \\
\hline & 60 & & 160 & 112 & 129 & \\
\hline \multirow{2}{*}{200} & 30 & \multirow{2}{*}{4220} & 121 & 106 & 89 & \\
\hline & 60 & & 113 & 10 & 81 & \\
\hline
\end{tabular}


The comparison of two treatment processes: in process one, the oil content of water samples of inclined tube separator output is $39-56 \mathrm{mg} / \mathrm{L}$ with the water clarifier BHQ-04 of $50-100 \mathrm{mg} / \mathrm{L}$, which is far more less than that of $113-210 \mathrm{mg} / \mathrm{L}$ in process two. And the filtered water samples with the oil content of $100 \mathrm{mg} / \mathrm{L}$ can not reach the injecting water quality standard. The comparative analysis reveals the process with electrochemical technology shows up a better oil removal efficiency. The specific mechanism of electrochemical removal oil in the period of the process operating is free radical $\left(\cdot \mathrm{OH}, \mathrm{HO}_{2} \cdot, \cdot \mathrm{O}_{2}\right)$ and strong oxidizing substances $\left(\mathrm{O}_{3}, \mathrm{H}_{2} \mathrm{O}_{2}\right.$, $\mathrm{ClO}^{-}$) produced on anode electrode can decompose polymer molecules into small molecules; meanwhile the micro bubbles produced on anode and cathode electrode will coalesce the emulsified oil into large oil droplets, at the same time the bubbles also bring the suspended solids and small molecules to the water surface to be removed. The oil removal rate of the complete treatment process forming by electrochemical technology and water clarifier is over 98\%, what is more important is the decreased dosages of BHQ-04 reduces the amount of viscoelastic sludge, providing a guarantee for the regular operation of the following process.

\subsection{Comparison of Filtered Water Quality}

The filtered water samples of six different dosages of water clarifier when the two processes are stable for 60min are used for the test of the particle size and suspended solids content to compare the water quality of the two processes.

Results of the particle diameter and median particle diameter of filtered water samples of six different dosages are presented graphically on Figure 2 and Figure 3.

Figure 2 and Figure 3 show 95\% particle diameter and median particle diameter of filtered water samples is less than $7.89 \mu \mathrm{m}$ and equal $2.26 \mu \mathrm{m}$ respectively with the water clarifier BHQ-04, which are far more less than those of the samples without BHQ-04 in process one; while 95\% particle diameter and median particle diameter of filtered water samples increase to $121.5 \mu \mathrm{m}$ and $87.1 \mu \mathrm{m}$ in process two. It presents the combination use of electrochemical technology and water clarifier can effectively remove the particulate material in wastewater.

Results of the suspended solid content of filtered water samples of six different dosages are presented graphically on Table 4.

Table 4 shows the suspended solid contents of filtered water samples vary from $13.79 \mathrm{mg} / \mathrm{L}$ to $15.52 \mathrm{mg} / \mathrm{L}$ with the water clarifier BHQ-04 of $150-200 \mathrm{mg} / \mathrm{L}$ in process two. And the treatment efficiency of the suspended solid content of $1.39-2.04 \mathrm{mg} / \mathrm{L}$ with the water clarifier BHQ-04 of $50-150 \mathrm{mg} / \mathrm{L}$ compared with that of $4.84 \mathrm{mg} / \mathrm{L}$ without the water clarifier BHQ-04 in process one indicates that electrochemical technology plays a key role in the treatment of wastewater containing polymer and the aggregation effect with water clarifier for fine particle is very obvious.

\subsection{Economic Indicator}

The dosage of water clarifier BHQ-04 of $380 \mathrm{mg} / \mathrm{L}$ is used for the treatment of wastewater containing polymer in an offshore platform, however the filtered water samples can not reach the injecting water quality standard

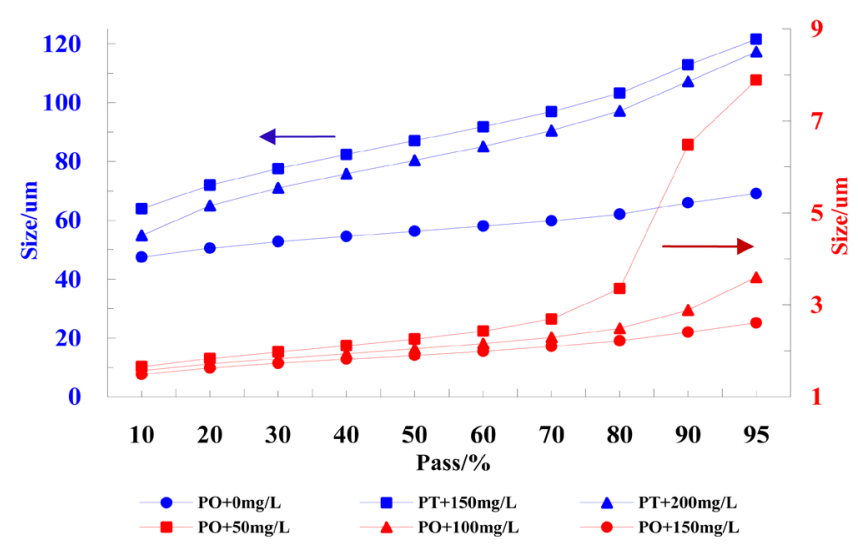

Figure 2. Changes of particle diameter after filtering in two kinds process. 


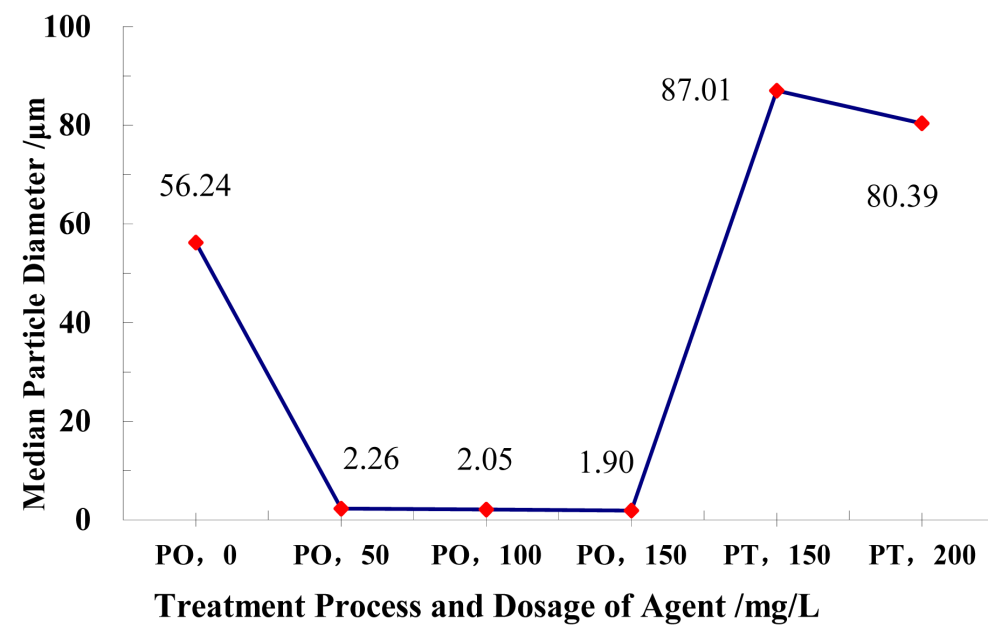

Figure 3. Changes trend of median particle diameter after filtering in two kinds process. (PO is Process One, PT is Process Two).

Table 4. Suspended solids analysis results after filtering of the whole process.

\begin{tabular}{|c|c|c|c|c|c|c|}
\hline \multirow{2}{*}{$\begin{array}{c}\text { Process } \\
\text { Dosages of } \mathrm{BHQ}-04 / \mathrm{mg} / \mathrm{L}\end{array}$} & \multicolumn{4}{|c|}{ Process One } & \multicolumn{2}{|c|}{ Process Two } \\
\hline & 0 & 50 & 100 & 150 & 150 & 200 \\
\hline Suspended Solids Content/mg/L & 4.84 & 2.04 & 2.09 & 1.39 & 15.52 & 13.79 \\
\hline
\end{tabular}

and the viscoelastic sludge forming by the adding reagent will cause blockage to the following processes after operating for a period of time. The process of electrochemical technology used in conjunction with BHQ-04 of $50 \mathrm{mg} / \mathrm{L}$ can effectually improve the treatment effect of wastewater to meet water quality standards with the power consumption of only $2.0 \mathrm{kw} \cdot \mathrm{h}$ per cubic meter wastewater. The oil content, median particle diameter and suspended solid content of filtered water samples are less than $11 \mathrm{mg} / \mathrm{L}, 2.26 \mu \mathrm{m}, 2.04 \mathrm{mg} / \mathrm{L}$ respectively. The test results show the process has a good economic benefit with $86.8 \%$ decrease of agent cost in the case of water quality standards.

\section{Conclusions}

1) A set of skid mounted treatment plant applying the process flow of cyclone mixed dosing $\rightarrow$ electrochemical removal oil $\rightarrow$ inclined tube removal oil $\rightarrow$ walnut shell filter was used for the field test of electrochemical treatment of wastewater containing polymer in offshore oilfield, and the treated water quality of the processes with and without electrochemical technology is as follows:

a) Process One with electrochemical technology: The oil content, median particle diameter and suspended solid content of filtered water samples which are clear and transparent are in a small range of 8 - $18 \mathrm{mg} / \mathrm{L}, 1.39$ $2.04 \mu \mathrm{m}, 1.9$ - $2.26 \mathrm{mg} / \mathrm{L}$ respectively with water clarifier BHQ-04 of 50 - $150 \mathrm{mg} / \mathrm{L}$.

b) Process Two without electrochemical technology: The oil content of water samples of inclined tube separator output is 113 - $210 \mathrm{mg} / \mathrm{L}$, and the median particle diameter and suspended solid content of filtered water samples which are pale yellow and opaque are in a wide range of $80-87 \mu \mathrm{m}, 13.79-15.52 \mathrm{mg} / \mathrm{L}$, respectively with water clarifier BHQ-04 of 150 - $200 \mathrm{mg} / \mathrm{L}$.

2) The combination use of electrochemical technology and water clarifier can effectively degrade the polymer and remove emulsified oil and particulate material in wastewater to decrease the oil content, turbidity, median particle diameter and suspended solid content of filtered water samples, and shows the obvious aggregation effect.

3) The process shows a good application prospect with a good economic benefit of agent cost decreased by $86.8 \%$, while the treated water samples can reach the injecting water quality standard without viscoelastic sludge produced in the process, providing a guarantee for the regular operation of the following process. 


\section{Acknowledgements}

The authors are grateful for financial support from the National Science and Technology Major Project of China (No. 2011ZX05024-004).

\section{References}

[1] Zhou, S.W., Han, M., Xian, W.T., et al. (2006) Application of EOR Technology by Means of Polymer Flooding in Bohai Oilfields. China Offshore Oil and Gas, 18, 386-389.

[2] Jiang, T. and Fang, J. (2012) Study on the Flocculants for Treating Polymer-Bearing Wastewater in SZ36-1 Oilfield. Industrial Water Treatment, 32, 81-83.

[3] Chen, W., Jing, B., Zhang, J., et al. (2012) Study on the Aggregative Properties of Polymer-Flooding Oil-Bearing Wastewater. Industrial Water Treatment, 32, 77-80.

[4] Shen, M.H. and Wang, J.B. (2009) Study on the Wastewater Treatment of Polymer Flooding Produced Water in Bohai Oilfield. Industrial Water Treatment, 29, 69-71.

[5] Jing, B., Zhai, L., Zhang, J., et al. (2014) Development of Clarifiers for Produced Water Used for Offshore Polymer Flooding Oilfields. Oil Forum, 33, 9-11.

[6] Zhang, J. (2013) An Effective Method for High Efficiency Treatment of Wastewater Containing Polymer in Offshore Oilfield. Oil-Gasfield Surface Engineering, 32, 9-10.

[7] Chen, W., Yin, X.Q., Zhang, J., et al. (2013) Experimental Study of Electrochemical Treatment of the Polymerflooding Oily Wastewater. State Key Laboratory of High Efficiency Development of Marine Oil. New Technology for High Efficiency Development of Offshore Heavy Oil. Petroleum Industry Press, Beijing, 367-374.

[8] Chen, W. and Mei, P. (2013) Electrochemical Techniques for Environmental Pollution Control. Petroleum Industry Press, Beijing.

[9] Qu, J.H. and Liu, H.J. (2007) Electrochemical Principle and Technology of Water Treatment. Science Press, Beijing.

[10] Yin, X.Q., Zhang, J., Jing, B., et al. (2012) Effect of Polymer Content of Polymer-Flooding Sewage Water on Equipment for Wastewater Treatment. Techniques and Equipment for Environmental Pollution Control, 6, 3499-3502.

[11] Yin, X.Q., Jing, B., Xiao, Q.Y., et al. (2012) Study on Inclined Tube Oil Eliminator Separation Efficiency Optimization for Polymer Wastewater LD10-1Viscous Crude Oil in Bohai. State Key Laboratory of High Efficiency Development of Marine Oil. New Technology for High Efficiency Development of Offshore Heavy Oil. Petroleum Industry Press, Beijing, 138-142.

[12] Yin, X.Q., Jing, B., Zhang, J., et al. (2014) Multifunctional oil Bearing Wastewater Treatment Plant: China, ZL 2012 10554801.3.

[13] Xiao, Q.Y., Yin, X.Q., Sun, P.J., et al. (2013) A Treatment Agent BHQ-402 Used for Wastewater Containing Polymer and Oil. Oilfield Chemistry, 30, 597-599.

[14] Yin, X.Q., Jing, B., Xiao, Q.Y., et al. (2013) Study on the Separation Efficiency of Inclined Tube Oil Removal-Filtration for Polymer Wastewater. Journal of Filtration \& Separation, 23, 1-3, 17.

[15] Yin, X.Q., Jing, B., Fu, J.X., et al. (2014) A Non Power Swirl Reactor for Oil Bearing Wastewater in Oil Field: China, ZL 20131 0120325. 9. 